\title{
A Meteorological Risk Assessment Model for Geological Disasters of Qinhuangdao
}

\author{
Lihua Sun, Xiuzhi Cao, Weimin Li, Tianyun Zhang \\ The Meteorological Bureau of Qinhuangdao, Qinhuangdao 066000, China \\ 秦皇岛市地质灾害气象因素风险评估 \\ 孙丽华, 曹秀芝, 李卫敏, 张天云 \\ 河北省秦皇岛市气象局, 秦皇岛 066000, 中国
}

\begin{abstract}
Using Qinhuangdao 1953-2017, 53 cases of geological disasters and disaster 3 to 7 days before the period of $24 \mathrm{~h}$, occur daily rainfall data, analyzed the spatial and temporal distribution of geological disasters and rainfall, rainfall intensity, rainfall duration and the relationship between the geological disasters. The results show that Geological disasters induced by meteorological factors mainly include debris flow. The northern part of Qinhuangdao has more geological disasters than the south and mountainous areas, and the concentration occurred in July and August, especially in late July and early August.Short-term heavy rainfall with a daily precipitation of more than $50 \mathrm{~mm}$ is the main meteorological influencing factor of geological disaster. Based on the geological disaster and rainfall relationship, disaster meteorological risk zoning is established, and the geological disaster rainfall model is established to provide scientific reference for government decision-making.
\end{abstract}

Keywords: geological disaster; Meteorological factors; risk assessment; storm

\section{摘要}

利用秦皇岛市1953-2017年53例地质灾害 资料及灾害发生期 $24 \mathrm{~h}$ 、发生前 3-7天逐日降水 资料, 分析了地质灾害发生的时空分布特征及
降水量、降水强度、降水持续时间与地质灾害 的关系。结果表明: 气象因素诱发的地质灾害 以泥石流为主, 秦皇岛市地质灾害北部多于南 部、山区多于平原, 集中发生在7-8月, 尤以7 月下旬至 8 月上旬最多。日降水量 $\geqslant 50 \mathrm{~mm}$ 以上的 短时强降雨是引发地质灾害的主要气象影响因 素。基于地质灾害与降雨关系进行灾害气象风 险区划, 建立地质灾害降雨模型, 为政府决策 提供科学参考, 对秦皇岛市地质灾害的提前预 警与防治具有重要意义。

关键词: 地质灾害; 气象因素; 风险评估; 暴 雨

\section{1. 引言}

地质灾害是指自然因素和人为活动引发的 危害人民生命和财产安全的与地质作用有关的 灾害 [1]。地质灾害的发生常给经济建设和人民 生命财产造成巨大损失, 是我国最为严重的自 然灾害之一。随社会经济发展和人类活动日益 增强, 地质灾害发生频率逐渐增高, 造成的人 员伤亡和经济损失逐渐增多, 某种意义上, 地 质灾害已经成为制约社会经济发展和人类安居 的重要因素 [2]。随环境问题越来越受到社会各 界重视, 地质灾害的提前预警与防治成为了很 重要的一项工作。地质灾害的发生是一个多因 素共同作用的复杂物理过程, 其形成原因错综 复杂。大量研究表明 [3-10], 地质灾害的诱发 因素分别是降雨、地震和人类工程活动, 其中 降雨是地质灾害发生的最主要因素。秦皇岛市 北依燕山, 南临渤海, 属燕山山脉东段丘陵地 区与山前平原地带, 地势北高南低, 形成北部 
山区一低山丘陵区一山前平原区一冲积平原区 一滨海平原区的地貌特征。该市地质环境条件 复杂, 地质灾害种类繁多, 是河北省地质灾害 易发区之一[11-12]。因此, 通过深入调研秦皇 岛市地质灾害现状、历史地质灾害的气象统计, 分析地质灾害的诱发因素、找出地质灾害与气 象要素的相关规律、危险度及对气象要素的适 应程度等, 建立地质灾害气象因素风险预警模 型, 为公众防灾自救和政府防灾管理提供科学 依据, 对有效指导防灾减灾、最大限度地减少 地质灾害造成的人员伤亡和财产损失具有重要 意义。

\section{2. 秦皇岛市地质灾害概况}

秦皇岛市总面积 $7812 \mathrm{~km} 2$, 其中山区面积 $5615 \mathrm{~km} 2$, 平原区面积 $2197 \mathrm{~km} 2$, 地质灾害种类 有滑坡、崩塌、泥石流、地面塌陷、地裂缝等, 包含了除地面沉降以外的全部地质灾害 7 个种 类, 危害较大的主要是泥石流地质灾害。该市 地质灾害分布不均匀, 北部山区较集中, 南部沿 海较少 (见图 1)。北部燕山山区地势险峻, 沟谷纵横, 主要发育崩塌、滑坡、泥石流、采 空塌陷、岩溶塌陷及地裂缝等突发性地质灾害, 崩塌、滑坡、泥石流几乎遍及整个山区; 采空 塌陷、岩溶塌陷及地裂缝主要分布在柳江盆地; 平原区以渐变性地质灾害为主, 主要发育有海 水入侵、海岸侵蚀等 [11-12]。《2017 年度秦 皇岛市地质灾害防治方案》中提到: 截止到 2017 年 11 月, 全市各类地质灾害隐患点共 250 处（崩塌 125 处、滑坡 35 处、泥石流 61 处、

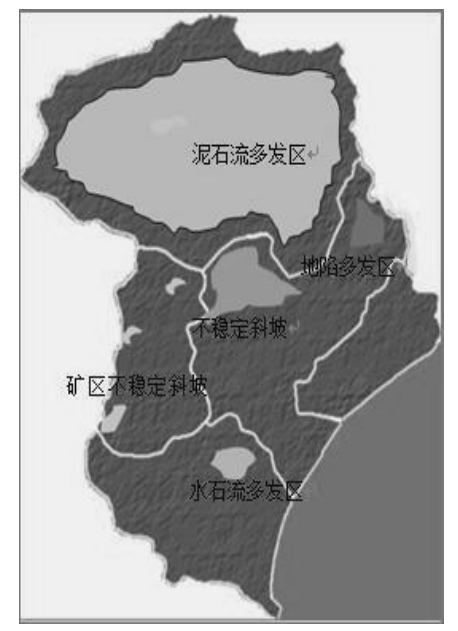

图 1: 秦皇岛市地质灾害隐患地理分布
地裂缝 7 处、地面塌陷 22 处), 直接威胁人口 3683 人, 直接威胁财产约 1.1 亿元。全市山区 尤以青龙满族自治县、抚宁区、卢龙县及市区 北部山区为泥石流、滑坡、崩塌地质灾害重点 防范区, 且泥石流主要分布在青龙境内、抚宁 的北部台营、大新寨山区。海港区石门寨镇、 驻操营镇柳江盆地是地面塌陷、地裂缝重点防 范区。

\section{3. 秦皇岛市地质灾害的时空分布}

\section{1 时间分布}

按发生地质灾害日期统计, 秦皇岛市 1953-2017年共发生地质灾害53起, 平均每年 0.82 起, 其中上世纪 $60 、 70$ 年代最少, 各为 5 起, 2001-2010年最多, 为12起, 2011-2017年 次多, 为 11 起, 说明随社会进步和工业化发展, 地质灾害的发生频次呈增加趋势。图2为秦皇岛 市地质灾害各月平均降水量及发生次数时间分 布, 由图可见: 秦皇岛市发生的地质灾害出现 在6-9月, 最早为 6 月 2 日, 最晚为 9 月 1 日, 主要 集中期为 $6 、 7 、 8$ 月, 尤其是 7 月下旬至 8 月上旬, 共出现地质灾害 27 次, 占总次数的 $51 \%$ 。而降水 也主要集中在这 3 个月 (即主汛期), 这 3 个月的 降水量占全年总降水量的 $70 \%$ 。相关研究表明 [3-10]: 降雨既是灾害发生的动力来源, 也是 其形成的主要诱发因素。降雨会使地下水位、 基质吸力发生改变, 也使岩土体内部结构、含 水量、应力状态、强度发生改变, 导致岩土体 强度明显降低。从秦皇岛市民政部门统计的灾 情记录看, 53起地质灾害的发生均与降水关系 十分密切, 没有 1 次地质灾害的发生是没有降水 的, 因此可以推断降雨是导致地质灾害发生的 主要自然诱因, 是引发当地地质灾害的重要原 因和充分条件。

\section{2 空间分布}

按地质灾害发生区域计算, 秦皇岛市所发 生的地质灾害以青龙满族自治县最多, 为 28 次, 卢龙次之, 为 19 次, 以上 2 县发生的地质灾害次 数占总次数的 $62 \%$, 抚宁 8 次, 昌黎最少为 1 次 (见 图3）。地质灾害发生次数的多少与地质地理 结构关系密切, 因秦皇岛市不稳定斜坡主要 分布在青龙和卢龙的矿区、抚宁北部的台营 镇部分地区, 当出现暴雨或强降水等有利天 气形势时, 应首先考虑以上地区是存在地质 


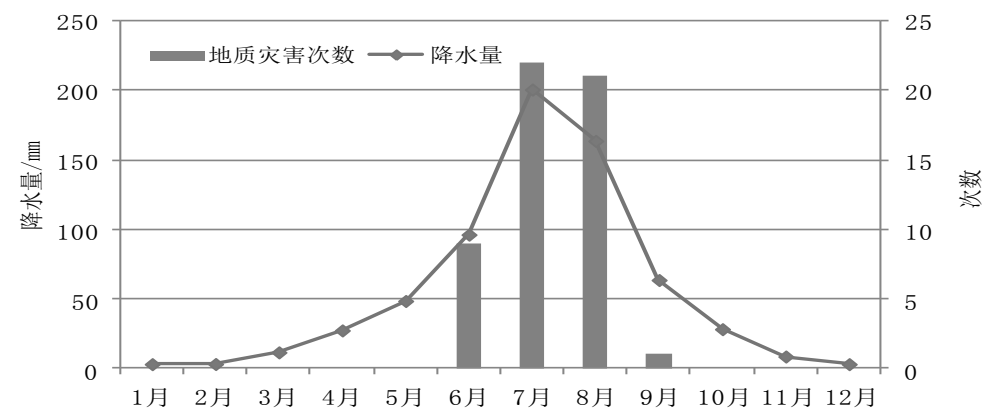

图 2: 秦皇岛市 1953-2017 年逐月平均降水量和地质灾害发生次数

灾害隐患的危险区域。

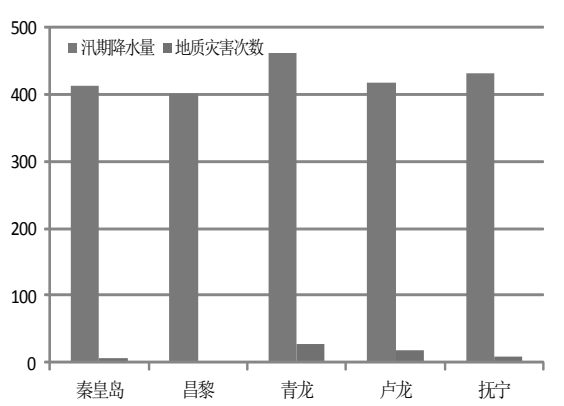

图 3: 秦皇岛市各县区汛期降水量和地质灾害发生次数

\section{4. 降水对地质灾害的诱发}

地质灾害的发生受内因和外因控制, 内因 是指地质灾害体所处的环境地质条件, 外因可 以通过影响内因来诱发地质灾害的发生。降雨 是导致地质灾害发生的主要自然诱因, 但不同 的降水量、降水强度、降水持续时间、降水累 积量会引起不同程度的地质灾害。只有当地质 体处于临界稳定状态或接近临界稳定状态时, 外因才能诱发地质灾害。对1953-2017年发生的
53起地质灾害对应其发生前 $24 \mathrm{~h} 、$ 前3-7 天的雨 量作统计分析。结果表明: 53起地质灾害均与 降水有关, 当天为大雨 $(25 \leqslant$ 雨量 $<50 \mathrm{~mm})$ 引发 地质灾害的有 3 例, 占 $5.6 \%$ 。当天为暴雨 (雨量 $\geqslant 50 \mathrm{~mm}$ ）引发地质灾害的有 14 例, 占 $26.4 \%$; 当天为大暴雨 (雨量 $\geqslant 100 \mathrm{~mm}$ ) 引发地质灾害的 有 22 例, 占 $41.5 \%$, 当天为特大暴雨 (雨量 $\geqslant$ $250 \mathrm{~mm}$ ）引发地质灾害的有 6 例, 占 $11.3 \%$, 当日 降雨量小于 $25 \mathrm{~mm}$ 且前3-7天出现连续性降雨发 生地质灾害的有 8 例, 占15\% (见表1)。也就是 说近 $80 \%$ 的地质灾害是由 24 小时内出现暴雨及 以上量级的降水引发的, 即短时强降雨是引发 该区域地质灾害的主要气象影响因素, 对地质 灾害具有明显的诱发效应, 其次分别是持续降 雨量和持续降雨日数。降雨量作为诱发滑坡、 泥石流地质灾害的重要因素, 很大程度上指示 了地质灾害发生的可能性, 一般来说, 在降雨 发生当天及前几天, 大部分地质灾害的发生都 会伴随降雨的发生, 并且规律性非常明显。

表1 1953-2017年秦皇岛市不同降水级别下地质灾害发生情况

\begin{tabular}{cccccc}
\hline 统计值 & \multicolumn{5}{c}{ 降水量级 $/ \mathrm{mm}$} \\
\cline { 2 - 6 } & $0-50$ & $50-100$ & $100-250$ & $\geqslant 250$ & 持续性降水 \\
\hline 灾害发生次数 & 3 & 14 & 22 & 6 & 8 \\
致灾率 $/ \%$ & 5.6 & 26.4 & 41.5 & 11.3 & 15 \\
\hline
\end{tabular}

\section{5. 秦皇岛市地质灾害气象因素风险评估}

\section{1地质灾害气象风险区划}

根据国土资源部和中国气象局的联合规 定, 按照未来24小时内地质灾害发生的可能性
大小, 将地质灾害气象预警分为五级: F1 级: 地质灾害发生的可能性很小; F2 级: 地质灾害 发生的可能性较小; F3 级 (注意级) : 地质灾 害发生的可能性较大; F4 级 (预警级) : 地质 
灾害发生的可能性大; F5 级（警报级）：地质 灾害发生的可能性很大, 其中 3 级及以上为地质 灾害气象预警信息发布级。基于秦皇岛市地质、 地理及岩土体结构特点, 结合地质灾害发生与 降水的关系分析, 对秦皇岛市进行地质灾害气 象风险等级区划 (图4)。该区划共分为 5 个级 别: 高风险、次高风险、中度风险、次低风险、 低风险等级, 北部山区为地质灾害高风险区, 由北向南地质灾害气象风险等级依次降低, 南 部沿海为地质灾害低风险区。

\section{2 地质灾害气象风险评估模型}

分析表明, 持续性降水容易造成山体滑坡, 而泥石流是持续性降水和短时暴雨共同造成 的, 尤其出现暴雨及以上量级降水时, 滑坡、 泥石流灾害发生率高, 也使崩塌、地面塌陷、 地裂缝加剧, 给人民生命财产安全带来威胁。 对1953 2017年秦皇岛市各种地质灾害共53个 个例和代表站雨量进行统计分析, 建立该市地 质灾害气象风险评估模型: 当 $24 h$ 达中雨量级
时, 定为 1 级风险; 当 $24 h$ 达中到大雨量级时, 定为 2 级风险; 当 $24 \mathrm{~h}$ 降水量50-100毫米时, 定 为 3 级风险; 日降水量 $100-150$ 毫米或连续 2 天降 水量大于 100 毫米时, 定为 4 级风险; 日降水量 大于 150 毫米或连续 3 天降水量大于 150 毫米时, 定为 5 级风险。其中 2 级以下为内部监测警示级 别, 不对外发布, 当达到3-5级时则由当地气象 部门联合国土资源部门在地质灾害气象预报预 警中共同对外发布。

气象预报人员可根据天气系统判断主要降 水落区、降水量级别, 依据地质灾害气象风险 评估模型, 确定地质灾害预警等级。分析表明, 出现华北气旋、冷浴、低槽冷锋、西南浴、副 高切变等系统时, 容易在北部山区出现暴雨、 强降水天气, 引发泥石流等地质灾害。依据以 上系统, 建立相应的天气预报指标, 从而判断 当地地质灾害气象风险等级。而台风登陆或台 风外围则影响山海关、海港区、北戴河区、抚 宁区、昌黎县等沿海地区, 要注意台风引起的

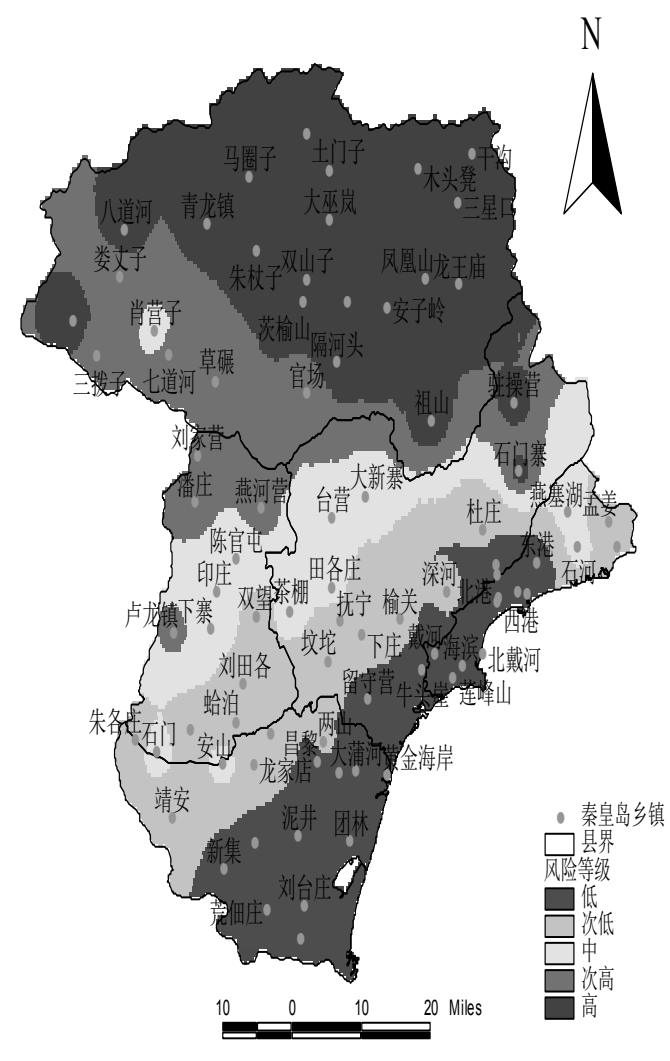

图 4: 秦皇岛市地质灾害气象风险区划 
风暴潮灾害。

\section{6. 结论}

（1）秦皇岛市地质灾害以泥石流为主, 北 部多于南部、山区多于平原, 7-8月为该市地质 灾害高发期, 尤以7月下旬至8月上旬最多。突 发性崩塌、滑坡、泥石流地质灾害与短时强降 水和持续性降水有极为密切的关系。当天为暴 雨引发的地质灾害占 $26.4 \%$, 当天为大暴雨引发 地质灾害占 $41.5 \%$, 可以认为短时强降雨是引发 该地地质灾害的主要气象影响因素。

（2）基于秦皇岛市地质、地理及岩土体结 构特点, 结合地质灾害发生与降水的关系分析, 完成秦皇岛市地质灾害气象风险等级区划, 确 定北部山区为地质灾害高风险区, 是存在地质 灾害隐患的危险区域。

(3)运用前期降水与未来降水预报相结合 来对地质灾害进行预报预警是可行的, 因此, 建立地质灾害气象风险评估模型, 依据天气系 统进行强降水落区预报对预防地质灾害具有指 导作用。

(4)应该指出的是地质灾害气象预报的准 确率目前仍然受很多方面的制约, 其中降水预 报的精确度以及正确判定地质灾害与降雨之间 的关系是最主要的问题。气象部门应与国土资 源部门合作, 收集灾害发生的逐时资料, 配合 逐时自动站雨量资料, 进一步完善地质灾害的 预报及风险评估方法。

\section{参考文献}

[1]张书余.地质灾害气象预报基础.北京:气象 出版社, 2005: 98一104.

[2]郑孝玉. 滑坡预报研究方法综述.世界地质, 2000,19(4):370.

[3]黄莉, 周云霞, 黄君健, 等.广西西南部地质 灾害气象因素风险评估. 防灾科技学院学 报, 2008,10(4): 79-82.

[4]景学义, 王开宇, 贾艳辉, 等. 哈尔滨市地质 灾害气象诱因分析及监测预警. 自然灾害 学报,2008,17(1):139-142.

[5]丁力,彭九慧, 谭国明.承德市地质灾害气象 预报方法初探.气象科技,2006,34(6):750-7 53.

[6] 裴惠娟,陈晋,李雯,等.甘肃省地质灾害风 险评估.灾害学,2017,32(2):97-102.
[7]尤凤春,史印山,郭丽霞.河北省山区地质灾 害气象预警系统.气象科技,2008,36(6):81 8-821.

[8]黄丽, 李奇,袁华东. 降水对湖北省地质灾害 发育程度的影响.资源环境与工程,2012,2 6(4):369-375.

[9]Guo S J. The Meteorological Disaster Ri sk Assessment Based on the Diffusion Mechanism. Journal of Risk Analysis an d Crisis Response, 2012, 2(2):124-130.

[10]章达华, 沈永生,刘建国,等.三明市前汛期 地质灾害与强降水的关系及其预报.暴雨 灾害,2011,30(2):182-187.

[11]郝文辉, 苏凯, 郭巨, 等. 秦皇岛市地质灾害 现状特征及防治体系建设探讨. 地下水, 20 16,38(5):176-178.

[12]吕玲莉. 秦皇岛市地质灾害风险区划的思 考与探索.中国环境管理干部学院学报, 20 10,20(6):39-41. 